\title{
The relationship between indoleamine 2,3-dioxygenase activity and post-stroke cognitive impairment
}

\author{
Allison B Gold ${ }^{1,2,3}$, Nathan Herrmann 1,2,3, Walter Swardfager ${ }^{1,4}$, Sandra E Black ${ }^{2,5,3}$, Richard I Aviv ${ }^{6}$, Gayla Tennen ${ }^{1,2}$, \\ Alexander Kiss ${ }^{7}$, Krista L Lanctôt ${ }^{1,2,3,4,8^{*}}$
}

\begin{abstract}
Background: Activation of indoleamine 2,3-dioxygenase (IDO) and higher concentrations of several kynurenine metabolites have been observed post-stroke, where they have been associated with increased mortality. While lower tryptophan or a higher ratio of kynurenine/tryptophan $(K / T)$ in peripheral blood have been associated with dementia and the severity of cognitive symptoms in Alzheimer's disease, the association between KTT ratios and post-stroke cognitive impairment (PSCl) has not been investigated.
\end{abstract}

Methods: Patients were recruited from the acute stroke unit of a general hospital within 1 month post-stroke. Assessments included the Standardized Mini-Mental State Examination (SMMSE) for cognition, the National Institutes of Health Stroke Scale (NIHSS) for stroke severity, and the Center for Epidemiological Studies-Depression Scale (CES-D) for depressive symptoms. Tryptophan and kynurenine concentrations were determined by highperformance liquid chromatography.

Results: A total of 41 patients with ischemic stroke ([mean \pm SD] age $72.3 \pm 12.2$ years, 53.7\% male, sMMSE $25.6 \pm$ 4.1, NIHSS $7.27 \pm 5.55$ ) were recruited. Higher $\mathrm{K} / \mathrm{T}$ ratios were associated with lower post-stroke global cognition (i. e. SMMSE scores; $\beta=-.327, P=.037)$. A backward stepwise elimination linear regression $\left(F_{1,40}=6.15, P=.005\right.$, adjusted $\left.R^{2}=.205\right)$ showed that the highest $K T$ ratio tertile $(\beta=-.412, P=.006)$ predicted lower sMMSE scores, controlling for age $(\beta=-.253, p=.081)$, with NIHSS $(\beta=-.027, P=0.859)$, and lesion volume $(\beta=-.066, P=0.659)$ removed from the model. In receiver operating characteristic analysis, a $\mathrm{K} / \mathrm{T}$ ratio of $78.3 \mu \mathrm{mol} / \mathrm{mmol}$ (top tertile) predicted significant cognitive impairment (SMMSE score $\leq 24$ ) with $67 \%$ sensitivity and $86 \%$ specificity (area under the curve $=0.730, p=.022$ ).

Conclusions: These data suggest an inflammatory response characterized by IDO activation may be relevant to the development of PSCl. Since the neuroactivity of kynurenine metabolites may be amenable to pharmacotherapeutic intervention, the $\mathrm{K} / \mathrm{T}$ ratio may be a clinically important biomarker.

\section{Background}

Stroke affects 15 million individuals annually world-wide, and the risk of having a stroke more than doubles each decade after the age of 55 [1]. Most stroke survivors live with residual impairments that diminish independence and quality of life [2]. For older patients with ischemic stroke, post-stroke cognitive impairment (PSCI) is

\footnotetext{
* Correspondence: krista.lanctot@sunnybrook.ca

'Neuropsychopharmacology Research Group, Sunnybrook Health Sciences Centre, Toronto, Ontario, Canada

Full list of author information is available at the end of the article
}

particularly important and frequent, occurring in approximately one third of all patients [3] and having a significant negative impact on rehabilitation outcomes [4], quality of life [5] and risk of dementia [6]. A recent meta-analysis has confirmed several risk factors, including previous symptomatic stroke, previous asymptomatic stroke seen on imaging, multiple stroke lesions, aphasia, stroke severity, and stroke location, are associated with PSCI as defined by Mini-Mental State Examination (MMSE) scores less than 24, Diagnostic and Statistical Manual of Mental Disorders IV (DSM-IV) or International Classification of

\section{Biomed Central}


Disease-10 (ICD-10) criteria, within 1 year after stroke [7]. The prevalence of post-stroke MMSE scores less than 24, indicative of significant cognitive impairment, was much higher than the prevalence of dementia diagnosed by standard criteria, which included the DSM-IV or ICD-10 [7]. The majority of these and other known risk factors for PSCI including older age, lower level of education, family history of dementia [8] are not readily amenable to treatment. Therefore, there is considerable need to identify pathophysiological mechanisms that may contribute to PSCI.

The systemic inflammatory response to acute ischemic stroke involves increases in several pro-inflammatory cytokines and C-reactive protein (CRP) [9-11], which have also been associated with the development of cognitive deficits and dementia in aging populations [12]. We have recently demonstrated a relationship between PSCI and two inflammatory biomarkers, CRP and interleukin-6 (IL-6) [13]. Pro-inflammatory cytokines can activate the indoleamine-2,3-dioxygenase (IDO) enzyme, leading to the depletion of tryptophan (TRP) and the production of kynurenine, increasing the kynurenine/ tryptophan $(\mathrm{K} / \mathrm{T})$ ratio in peripheral blood, which acts as a clinical measure of IDO activity [14]. Elevations in the $\mathrm{K} / \mathrm{T}$ ratio and in the concentrations of several kynurenine metabolites have been observed post-stroke, where they have been associated with mortality [15]. While lower peripheral blood tryptophan concentrations or higher K/T ratios have been associated with dementia and the severity of cognitive symptoms in Alzheimer's disease $[16,17]$, the association between $\mathrm{K} / \mathrm{T}$ ratios and PSCI has not been investigated.

Tryptophan metabolites along the kynurenine pathway can produce excitatory and oxidative neurotoxicity, but also protect neurons from inflammatory damage and attenuate excitatory neurotoxicity via NMDA receptor antagonism [18-23]. Therefore, it is of interest to determine whether kynurenine production might be associated with clinical cognitive outcomes, and if so, at which concentrations.

The purpose of this study was to test the hypothesis that IDO activation is associated with the presence of cognitive symptoms post-stroke. We measured plasma concentrations of kynurenine and tryptophan in acute ischemic stroke patients and explored the relationship between the $\mathrm{K} / \mathrm{T}$ ratio and cognitive deficits, as measured by the MMSE, a commonly used cognitive screening instrument [24].

\section{Methods}

\section{Study design}

This cross-sectional observational study recruited participants admitted to an acute care regional stroke centre within 30 days of an ischemic stroke. The study was approved by local research ethics boards, and all participants provided written informed consent.

\section{Recruitment}

Consecutive patients meeting the National Institute of Neurological and Communicative Disorders and Stroke (NINCDS) [25] and World Health Organization Multinational Monitoring of Trends and Determinants in Cardiovascular Disease (WHO-MONICA) [26] criteria for stroke were invited to participate in this study. Acute ischemic infarcts were verified from computed tomography (CT) or magnetic resonance imaging (MRI) reports performed at the time of admission in all patients. Inclusion criteria also required participants to speak and understand English. Exclusion criteria were: pre-stroke diagnosis of dementia or significant cognitive impairment, primary hemorrhagic stroke (which have a different etiology and clinical course), decreased level of consciousness, severe aphasia or dysarthria (which would interfere with the ability to complete the study assessments), significant acute medical illness (which would be associated with significant inflammatory burden of its own; e.g. infection, autoimmune disease, cancer), significant acute neurological illness other than stroke, and the presence of a premorbid axis I psychiatric disorder. A history of major depression was permitted, and controlled for in statistical analyses as needed.

\section{Assessments}

After obtaining written informed consent, the MiniMental State Examination (MMSE) [24] was administered. The MMSE was selected as a cognitive screening instrument because it is a brief, widely used, and validated scale in acute care settings [27]. Although not sensitive to subtle cognitive impairment, scores on the MMSE correlate strongly with the more thorough yet lengthy CAMCOG (cognitive and self-contained part of the Cambridge Examination for Mental Disorders of the Elderly) in a stroke rehabilitation setting [28]. Given the exploratory nature of this study and the potentially low tolerability of a longer assessment in an acute stroke setting, a brief yet validated and clinically meaningful cognitive instrument was selected. MMSE scores were adjusted according to physical ability post-stroke as recommended by the Standardized Mini Mental State Examination (sMMSE) [29].

Stroke severity was assessed using the National Institutes of Health Stroke Scale (NIHSS) [30], either as completed by clinicians at the time of patient admission and obtained through chart review, or extracted from the chart information using a standardized method as has been done before [31]. Depressive symptoms were assessed using the Center for Epidemiological Studies- 
Depression Scale (CES-D) [32]. Information regarding demographic characteristics and medical history was collected via chart review and consultation with participants.

\section{Blood sampling and plasma analyses}

Fasting blood was collected via venipuncture in EDTA (ethylenediaminetetraacetic acid) BD Vacutainer ${ }^{\circledR}$ (New Jersey, USA) tubes at 7:30 am \pm 30 minutes on the morning after the clinical assessments were conducted. Blood samples were centrifuged at $1000 \times g$ for $10 \mathrm{~min}$ at $4^{\circ} \mathrm{C}$ and plasma was separated and stored at $-80^{\circ} \mathrm{C}$ until the time of assay. Tryptophan and kynurenine concentrations were determined by high-performance liquid chromatography (HPLC), as described elsewhere [33,34]. Tryptophan was measured by isocratic reverse phase HPLC without derivatization and fluorescence detection. For kynurenine, an equal volume of 3\% perchloric acid was used for protein precipitation. After centrifugation, the concentration of ${ }_{L}$-kynurenine in the supernatant was measured by HPLC with UV detection at $258 \mathrm{~nm}$. The mobile phase consisted of $9 \%$ acetonitrile in $0.05 \mathrm{M}$ potassium phosphate mono basic, pumped through a reverse phase $5 \mu \mathrm{m}$ ODS column, $250 \mathrm{~mm} \times 4.6 \mathrm{~mm}$ (Symmetry; Waters Corporation, Milford, Massachusetts, United States of America). Biochemical assays were performed blinded to all clinical information.

Lesion characteristics were determined from CT scans obtained without a contrast agent on a General Electric LightSpeed VCT series scanner (General Electric Healthcare, Waukesha, WI). Ischemic lesions were manually traced on these images using Medical Image Processing, Analysis, and Visualization (MIPAV; National Institutes of Health, Bethesda, MD). Stroke volume was calculated using a slice-by-slice planimetric methodology employing these manual lesion tracings.

\section{Statistical Analysis}

Continuous measures were summarized using means and standard deviations whereas categorical measures were summarized using percentages. Tryptophan and kynurenine were determined by mass and converted to molar units. Their quotient was multiplied by 1000 to obtain the $\mathrm{K} / \mathrm{T}$ ratio in units of $\mu \mathrm{mol} / \mathrm{mmol}$. The naturally skewed nature of the data resulted in absolute values of kurtosis and skewedness being greater than 2 $\mathrm{SD}$ of the error, so K/T values were log transformed to obtain a normal distribution. All statistical analyses were performed using transformed values or tertiles.

For initial descriptive analyses, the relationship between sMMSE scores and K/T ratio, as well as possible covariates such as age, gender, stroke severity, time since stroke, level of education, cumulative burden of cerebrovascular risk factors (i.e. the number of vascular risk factors including diabetes, smoking, hypertension, hyperlipidemia, and obesity summed), and lesion volume were analyzed with bivariate Pearson correlations or analyses of variance (ANOVA) as appropriate.

To test our hypothesis, a backward elimination multiple linear regression model was used to examine the association between $\mathrm{K} / \mathrm{T}$ ratios and SMMSE scores as continuous variables with age, stroke severity, and lesion volume entered into the initial model. In addition, to determine if an elevated $\mathrm{K} / \mathrm{T}$ ratio predicted poorer sMMSE scores, patients were divided into tertiles based on the $\mathrm{K} / \mathrm{T}$ ratio, and a backward elimination multiple linear regression analysis with patients dichotomized by those in the top tertile vs. others was used. A removal criterion of $\mathrm{P}>.1$ was used in backward regression models. Finally, a receiver operating characteristic (ROC) analysis was performed to determine a K/T ratio optimum (sensitivity vs. specificity) that predicts significant cognitive impairment (sMMSE score $\leq 24$ ) [7].

Given the strong commonly observed relationships between depressive symptoms, inflammatory activation [35] and cognitive impairment [36,37], the impact of depressive symptoms or a history of depression on the observed relationship between $\mathrm{K} / \mathrm{T}$ ratio top tertile and sMMSE was explored by adding CES-D scores or history of depression into the final regression model. Similarly, given the observed relationship between vascular risk factors and cognitive impairment [38], the number of cerebrovascular risk factors was added to the final regression model. Time since stroke, gender, and level of education were also explored as covariates.

All patient information was de-identified for statistical analyses using SPSS statistical software (version 17; SPSS Inc., Chicago, Illinois).

\section{Sample size and study power calculation}

A sample size of 39 subjects achieves a power of $80 \%$ to detect an association between the $\mathrm{K} / \mathrm{T}$ ratio and sMMSE scores with an effect size $\left(\mathrm{f}^{2}\right)$ of 0.35 given a two-tailed significance level of 0.05. A sample size of at least 41 subjects allows adjustment with up to 3 additional covariates.

\section{Results}

A total of 41 patients (mean \pm SD age $72.3 \pm 12.2$ years, $53.7 \%$ male) were recruited. Tryptophan and kynurenine chromatograms appeared as previously described [33]. The mean K/T ratio was $67.40 \pm 42.46 \mu \mathrm{mol} / \mathrm{mmol}$. Scores on the sMMSE ranged from 13 to 30, with 29.3\% of the sample having evidence of significant cognitive impairment (sMMSE $\leq 24)$. Table 1 reports the results of correlations with SMMSE scores and $\mathrm{K} / \mathrm{T}$ ratios, as well as between sMMSE scores and demographic and lesion characteristics. In addition to $\mathrm{K} / \mathrm{T}$ ratio, time 
Table 1 Clinical characteristics and correlations with cognitive impairment $(n=41)$

\begin{tabular}{|c|c|c|c|c|}
\hline & MEAN \pm SD OR $\%$ & RANGE & $r$ - OR F* VALUE & P-VALUE $^{\dagger}$ \\
\hline Age & $72.3 \pm 12.2$ years & $39-91$ years & -0.27 & 0.08 \\
\hline Gender & $53.7 \%$ male & & 1.83 & 0.18 \\
\hline MMSE & $25.6 \pm 4.1$ & $13-30$ & - & - \\
\hline NIHSS & $7.27 \pm 5.55$ & $0-21$ & -0.08 & 0.63 \\
\hline CES-D & $13.8 \pm 12.8$ & $0-48$ & -0.09 & 0.59 \\
\hline History of Depression & $7.3 \%$ & & 0.35 & 0.56 \\
\hline Living Alone & $24.4 \%$ & & 0.06 & 0.81 \\
\hline Level of Education > high school & $46.3 \%$ & & 6.64 & 0.01 \\
\hline Time Since Stroke & $9.17 \pm 5.03$ days & 4-26 days & -0.34 & 0.03 \\
\hline \multicolumn{5}{|l|}{ Cerebrovascular Risk Factors } \\
\hline Hypertension & $85.4 \%$ & & 4.53 & 0.04 \\
\hline Diabetes & $26.8 \%$ & & 0.21 & 0.65 \\
\hline Hyperlipidemia & $34.1 \%$ & & 0.41 & 0.52 \\
\hline Obesity (BMI $\left.\geq 30 \mathrm{~kg} / \mathrm{m}^{2}\right)$ & $31.7 \%$ & & 2.17 & 0.15 \\
\hline Smoking & $22.0 \%$ & & 0.10 & 0.75 \\
\hline Total number risk factors & $2.15 \pm 1.28$ & $0-5$ & -0.21 & 0.19 \\
\hline Lesion Volume $\left(\mathrm{cm}^{3}\right)$ & $31.72 \pm 55.09$ & $0.250-287.58$ & -0.05 & 0.76 \\
\hline KT ratio ${ }^{\ddagger}$ & $67.40 \pm 42.46$ & $14.04-203.75$ & -0.33 & 0.04 \\
\hline
\end{tabular}

Abbreviations: MMSE, Mini-Mental State Examination; NIHSS, National Institutes of Health Stroke Scale; CES-D, Center for Epidemiological Studies-Depression Scale; BMI, body mass index; $\mathrm{K} / \mathrm{T}$ ratio, Kynurenine/Tryptophan ratio.

${ }^{*} \mathrm{r}$ or $\mathrm{F}$ values and their corresponding ${ }^{\dagger} \mathrm{p}$-values reflect the results of bivariate Pearson correlations with sMMSE scores for continuous variables and ANOVA between SMMSE scores -for categorical variables; ${ }^{\ddagger}$ values reflect the mean \pm SD of the detectable samples in each group.

since stroke and level of education were associated with sMMSE scores, with a trend for age to be significantly associated (Table 1). No association between lesion volume and sMMSE scores was found.

The bivariate correlation between sMMSE scores and the $\mathrm{K} / \mathrm{T}$ ratio persisted $(\beta=-.327, \mathrm{P}=.037)$ in a backward stepwise elimination linear regression where age, lesion volume, and stroke severity were removed from the model (adjusted $\mathrm{R}^{2}=.084$ ). When patients were dichotomized by those in the highest $\mathrm{K} / \mathrm{T}$ ratio tertile versus others, being in the top tertile emerged as a significant predictor of sMMSE scores $(\beta=-.412, P=.006)$ when controlling for age $(\beta=-.253, P=.081)$ with stroke severity $(\beta=-.027$, $\mathrm{P}=0.859)$ and lesion volume $(\beta=-.066, \mathrm{P}=0.659)$ removed from the final model (adjusted $\mathrm{R}^{2}=.205, \mathrm{~F}_{1,40}=6.15, \mathrm{p}=$ .005; Table 2). When exploring gender, time since stroke, level of education, number of cerebrovascular risk factors, history of depression, or CES-D scores as covariates, the

Table 2 Linear regression model predicting sMMSE scores*

\begin{tabular}{lcccc}
\hline & $\mathbf{B}$ & Std. Error & $\boldsymbol{\beta}$ & $\mathbf{P}$ \\
\hline KT top tertile & -3.61 & 1.28 & -.410 & $.008^{*}$ \\
NIHSS & -.020 & .111 & -.027 & .859 \\
Age & -.085 & .049 & -.254 & .088 \\
Lesion Volume & $-4.95 \mathrm{E}-6$ & .000 & -.066 & .659 \\
\hline
\end{tabular}

*Starting block with all covariates entered (overall adjusted $\mathrm{R}^{2}=.167, \mathrm{~F}_{1,40}=$ 3.01, $\mathrm{p}=.031)$. After backward elimination $(\mathrm{p}>.1), \mathrm{K} / \mathrm{T}$ ratio top tertile $(\beta=$ $-.412, p=.006)$ and age $(\beta=-.253, P=.081)$ remained in the model (overall $F_{1,40}=6.15, p=.005$, adjusted $R^{2}=.205$ ). association between the $\mathrm{K} / \mathrm{T}$ ratio top tertile and sMMSE scores remained significant $(\mathrm{P}<.018)$. A plot depicting the relationship between the $\mathrm{K} / \mathrm{T}$ tertiles and sMMSE scores is provided in Figure 1.

In an ROC curve, a $\mathrm{K} / \mathrm{T}$ ratio of $78.3 \mu \mathrm{mol} / \mathrm{mmol}$ predicted the presence of an sMMSE score $\leq 24$ with $67 \%$ sensitivity and $86 \%$ specificity (Figure 2 ). The area under

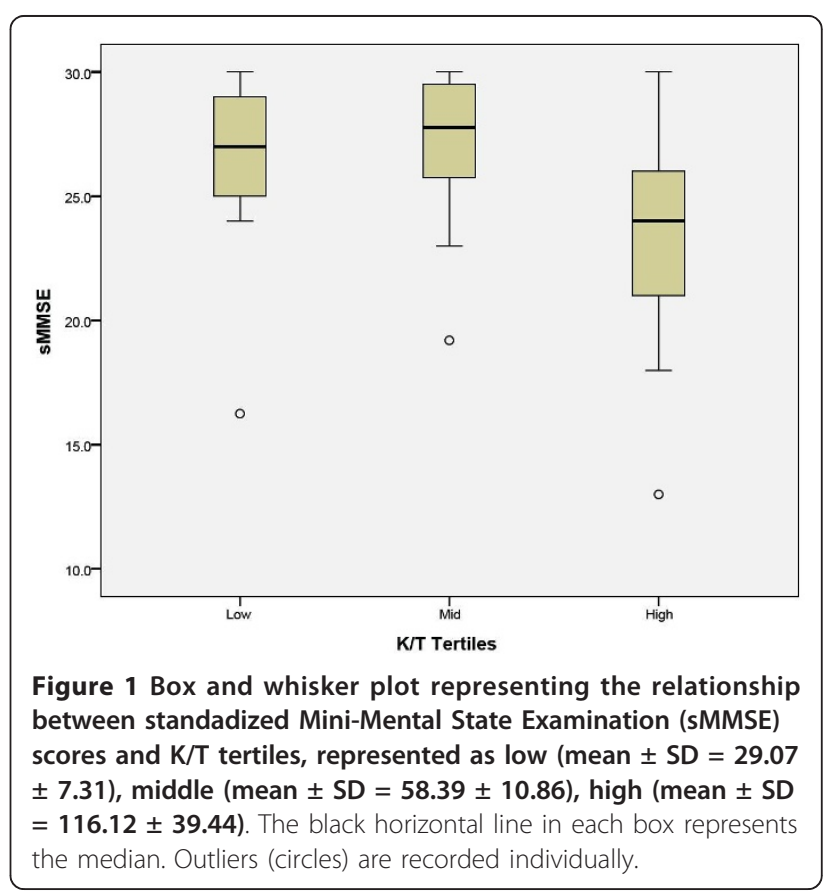




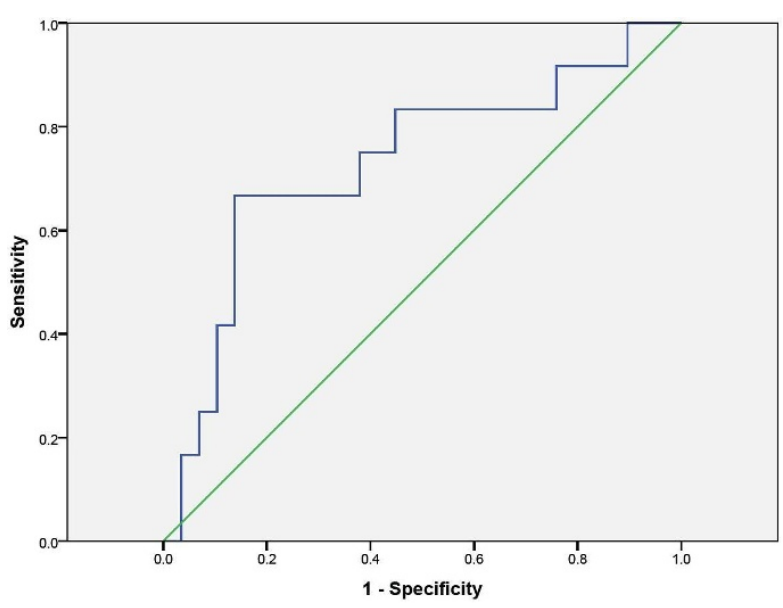

Figure 2 Optimal $\mathrm{K} / \mathrm{T}$ to detect significant cognitive impairment. Receiver Operating Characteristic Curve. A K T ratio of $78.3 \mu \mathrm{mol} / \mathrm{mmol}$ predicted significant cognitive impairment (SMMSE score $\leq 24$ ) with $67 \%$ sensitivity and $86 \%$ specificity. Area under the curve $=.730[.548, .912]$; Std Error $=.093, p=.022$.

the curve was .730 , indicating that $73.0 \%$ of the subjects will have a $\mathrm{K} / \mathrm{T}$ ratio that correctly ranks their likelihood of having an sMMSE score $\leq 24$.

\section{Discussion}

This study demonstrates an association between elevated $\mathrm{K} / \mathrm{T}$ ratios and the extent of cognitive impairment among acute ischemic stroke patients. Age, stroke severity and lesion volume did not significantly modify this relationship suggesting that the clinical importance of the $\mathrm{K} / \mathrm{T}$ ratio may extend beyond their relationships with these established risk factors for PSCI. The association between the $\mathrm{K} / \mathrm{T}$ ratio and cognition following acute stroke was sufficiently robust to be detected with the MMSE, a practical and clinically meaningful cognitive screening instrument.

Inflammatory activation is a key process in the ischemic cascade that leads to secondary brain damage [39]. We have previously reported that plasma CRP concentrations were able to explain $20 \%$ of the variance in MMSE scores among acute stroke patients and that plasma IL-6 concentrations also predicted MMSE scores [13]. Interestingly, high plasma concentrations of the pleiotrophic cytokine, IL-6, have been associated with a greater lesion volume [40], however lesion volume did not predict sMMSE scores in our population. Proinflammatory cytokines induce the expression of IDO which catalyzes the committal and rate-limiting step in the production of kynurenine from tryptophan. In the present study, having a $\mathrm{K} / \mathrm{T}$ ratio in the top tertile explained $21 \%$ of the variance in MMSE scores.

An elevated $\mathrm{K} / \mathrm{T}$ ratio has been associated with inflammatory and neurodegenerative conditions and with clinically important outcomes, including mortality in the very old [41], poorer cognitive function in those with Alzheimer's disease [17], and the severity of depressive symptoms in those receiving interferon therapy [42] or in those with cardiovascular disease [43]. The K/T ratio and poorer MMSE scores may be related to the burden of neurotoxic or neuroactive metabolites such as quinolinic acid (QUIN), an NMDA receptor agonist and excitatory neurotoxin, 3-hydroxyanthranilic acid, an oxidative neurotoxin, or kynurenic acid (KYNA), an antagonist at both NMDA and $\alpha 7$ cholinergic receptors. The production of these neuroactive metabolites has been previously associated with depression $[44,45]$, cognitive impairment, and deficits in learning, retrieval, and long-term memory $[40,46]$. For instance, the concentration of KYNA is elevated in the caudate nucleus and putamen of Alzheimer disease patients [47] and it has been suggested that NMDA or $\alpha 7$ cholinergic inhibition by KYNA might impair learning and memory [48]. In a study by Widner et al., Alzheimer's disease patients showed significantly higher peripheral blood $\mathrm{K} / \mathrm{T}$ ratios as compared to agematched controls and Alzheimer's disease patients with the lowest MMSE scores had significantly higher K/T ratios than those with the highest MMSE scores [17]. A second study by Gulaj et al. did not find a correlation between $\mathrm{K} / \mathrm{T}$ ratios and MMSE scores; however they observed an association between the KYNA/KYN ratio and MMSE scores, suggesting a possible protective effect of KYNA relative to the production of kynurenine and other metabolites [16]. This effect may be attributable to opposing effects of KYNA and quinolinic acid at NMDA or $\alpha 7$ nicotinic cholinergic receptors. The association between increased concentrations of kynurenine metabolites, especially KYNA and 3-hydroxyanthranilic acid, and mortality observed post-stroke [15] suggests the potential clinical importance of these metabolites in this population.

Identification of the $\mathrm{K} / \mathrm{T}$ ratio as a PSCI biomarker may represent an important step in improving stroke outcomes because the kynurenine metabolites might be amenable to pharmacological manipulation [23]. In the central nervous system, kynurenine aminotransferase II, expressed primarily in astrocytes, is responsible for KYNA synthesis while kynurenine 3-monooxygenase (KMO) produces the 3-hydroxykynurenine metabolite that gives rise to QUIN, predominantly from the microglia [49]. In animal models of cerebral ischemia, administration of kynurenine sulfate exerts neuroprotective effects and notably increases cerebral concentrations of KYNA [50,51]. It is now appreciated that cerebral 3hydroxykynurenine and quinolinic acid concentrations can be manipulated, selectively without altering KYNA concentrations, by inhibition of KMO [49], an approach 
which shows neuroprotective effects in animal models of cerebral ischemia [19]. In addition, a newly synthesized compound, ZL006, which acts downstream of NMDA receptor activation, has been demonstrated to ameliorate focal ischemic cerebral damage induced by middle cerebral artery occlusion in mice and rats [52]. The implication of endogenous excitotoxicity in the present study suggests that ZL006 might also be evaluated to improve cognitive outcomes.

In the present study, the $\mathrm{K} / \mathrm{T}$ ratio was able to identify subjects at risk of significant PSCI (i.e. those with sMMSE scores $\leq 24)$. While larger studies would be needed to confirm a clinically important cut-off value for the $\mathrm{K} / \mathrm{T}$ ratio, the ROC presented in the present study suggested a $67 \%$ sensitivity and $86 \%$ specificity for a $\mathrm{K} / \mathrm{T}$ ratio cut-off of $78.3 \mu \mathrm{M} / \mathrm{mM}$. While higher $\mathrm{K} / \mathrm{T}$ ratios were associated with lower MMSE scores in the entire population, this effect was most significant for subjects with a $\mathrm{K} / \mathrm{T}$ ratio in the highest tertile. A K/T ratio in this range is comparable to that found in subjects with HIV-1 infection in association with cognitive symptoms and AIDS dementia complex [53-55], but much higher than that found in normal healthy aged controls [15] or subjects with cardiovascular disease without a history of stroke [43]. If replicated in larger populations, these data suggest potential clinical utility of the $\mathrm{K} / \mathrm{T}$ ratio as a discriminating biomarker.

This study demonstrates a relationship between cognitive impairment and activation of the kynurenine pathway post-stroke. It is, however, limited by its use of a brief cognitive screening instrument and a relatively small sample size. Although stroke severity was assessed and included as a covariate, the timing of administration of the NIHSS relative to the stroke and cognitive assessment varied between assessments. Because NIHSS scores commonly fluctuate post-stroke, this measure may not have been adequate to control for stroke severity. However, in recognition of this, we also evaluated lesion volume and found that it was not significantly related to the severity of PSCI in this population. Additionally, the type of cognitive impairment observed post-stroke varies; often including deficits in measures of global cognition, as well as domain-specific impairments involving executive function, language, visuospatial ability, and memory [56]. Some previously identified risk factors for the development of PSCI, including family history of dementia and individual cardiovascular risk factors [8], could not be controlled for given the sample size. Although all efforts were made to control for potentially confounding variables, pre-stroke cognitive capacity and white matter disease burden were not assessed. Finally, the cross-sectional design of this study was useful in establishing an initial relationship between PSCI and elevated K/T ratios post-stroke, but subsequent longitudinal studies will be necessary to determine the value of $\mathrm{K} / \mathrm{T}$ ratio in predicting long-term cognitive outcomes.

\section{Conclusions}

In summary, an acute inflammatory response characterized by IDO activation may be relevant to the development of PSCI. Since the neuroactivities of kynurenine metabolites may be amenable to pharmacotherapeutic intervention, the $\mathrm{K} / \mathrm{T}$ ratio may be a clinically important biomarker. Longitudinal observational and intervention studies will improve our understanding of the role of IDO activity in PSCI.

\section{Acknowledgements}

This study was supported by the Heart and Stroke Foundation of Canada (T6383 and NA5857) and the Alzheimer Society of Canada (10 61). The authors gratefully acknowledge the Heart and Stroke Foundation Centre for Stroke Recovery for fellowship support for ABG as well as Amy Wong, MSC, and Philip Francis, MSc, for their contributions to recruitment and neuroimaging, respectively.

\section{Author details}

${ }^{1}$ Neuropsychopharmacology Research Group, Sunnybrook Health Sciences Centre, Toronto, Ontario, Canada. ${ }^{2}$ Brain Sciences Research Program, Sunnybrook Health Sciences Centre, Toronto, Ontario, Canada. ${ }^{3}$ Heart and Stroke Foundation Centre for Stroke Recovery, Toronto, Ontario, Canada. ${ }^{4}$ Department of Pharmacology/Toxicology, University of Toronto, Toronto, Ontario, Canada. ${ }^{5}$ Department of Medicine (Neurology), University of Toronto, Toronto, Ontario, Canada. ${ }^{6}$ Department of Medical Imaging (Neuroradiology), University of Toronto, Toronto, Ontario, Canada. ${ }^{7}$ Institute for Clinical Evaluative Sciences, Toronto, Ontario, Canada. ${ }^{8}$ Department of Psychiatry, University of Toronto, Ontario, Canada.

\section{Authors' contributions}

This study is based on the original idea of $\mathrm{KLL}$ and $\mathrm{NH}$. ABG participated in coordination and $A B G$ and WS performed the statistical analysis and wrote the manuscript. KLL, NH, SEB, GT, and AK made contributions to conception and design and analysis and interpretation of data. RIA provided neuroimaging data. All authors read and approved the final manuscript.

\section{Competing interests}

The authors declare that they have no competing interests with respect to the authorship and/or publication of the article.

Received: 25 November 2010 Accepted: 16 February 2011 Published: 16 February 2011

\section{References}

1. Lloyd-Jones D, Adams R, Carnethon M, De Simone G, Ferguson TB, Flegal K, Ford E, Furie K, Go A, Greenlund K, Haase N, Hailpern S, Ho M, Howard V, Kissela B, Kittner S, Lackland D, Lisabeth L, Marelli A, McDermott M, Meigs J, Mozaffarian D, Nichol G, O'Donnell C, Roger V, Rosamond W, Sacco R, Sorlie P, Stafford R, Steinberger J, Thom T, Wasserthiel-Smoller S, Wong N, Wylie-Rosett J, Hong Y: Heart disease and stroke statistics-2009 update: a report from the American Heart Association Statistics Committee and Stroke Statistics Subcommittee. Circulation 2009, 119:480-486.

2. Nakayama H, Jørgensen HS, Raaschou HO, Olsen TS: The influence of age on stroke outcome. The Copenhagen Stroke Study. Stroke 1994, 25:808-813.

3. Tatemichi TK, Desmond DW, Stern Y, Paik M, Sano M, Bagiella E: Cognitive impairment after stroke: frequency, patterns, and relationship to functional abilities. J Neurol Neurosurg Psychiatry 1994, 57:202-207.

4. Pohjasvaara T, Vataja R, Leppavuori A, Kaste M, Erkinjuntti T: Cognitive functions and depression as predictors of poor outcome 15 months after stroke. Cerebrovasc Dis 2002, 14:228-233. 
5. Nys GM, van Zandvoort MJ, van der Worp HB, de Haan EH, de Kort PL, Jansen BP, Kappelle $L$ : Early cognitive impairment predicts long-term depressive symptoms and quality of life after stroke. J Neurol Sci 2006, 247:149-156.

6. Rockwood K, Howard K, MacKnight C, Darvesh S: Spectrum of disease in vascular cognitive impairment. Neuroepidemiology 1999, 18:248-254.

7. Pendlebury ST, Rothwell PM: Prevalence, incidence, and factors associated with pre-stroke and post-stroke dementia: a systematic review and meta-analysis. Lancet Neurol 2009, 8:1006-1018.

8. Khedr EM, Hamed SA, El-Shereef HK, Shawky OA, Mohamed KA, Awad EM, Ahmed MA, Shehata GA, Eltahtawy MA: Cognitive impairment after cerebrovascular stroke: Relationship to vascular risk factors. Neuropsychiatr Dis Treat 2009, 5:103-116.

9. Kostulas N, Pelidou SH, Kivisakk P, Kostulas V, Link H: Increased IL-1beta, IL8, and IL-17 mRNA expression in blood mononuclear cells observed in a prospective ischemic stroke study. Stroke 1999, 30:2174-2179.

10. Tarkowski E, Rosengren L, Blomstrand C, Wikkelso C, Jensen C, Ekholm S, Tarkowski A: Early intrathecal production of interleukin- 6 predicts the size of brain lesion in stroke. Stroke 1995, 26:1393-1398.

11. Liebau C, Baltzer AW, Schmidt S, Roesel C, Karreman C, Prisack JB, Bojar H, Merk $\mathrm{H}$ : Interleukin-12 and interleukin-18 induce indoleamine 2,3dioxygenase (IDO) activity in human osteosarcoma cell lines independently from interferon-gamma. Anticancer Res 2002, 22:931-936.

12. Schram MT, Euser SM, de Craen AJ, Witteman JC, Frolich M, Hofman A, Jolles J, Breteler MM, Westendorp RG: Systemic markers of inflammation and cognitive decline in old age. J Am Geriatr Soc 2007, 55:708-716.

13. Rothenburg LS, Herrmann N, Swardfager W, Black SE, Tennen G, Kiss A, Gladstone DJ, Ween J, Snaiderman A, Lanctôt KL: The relationship between inflammatory markers and post stroke cognitive impairment. J Geriatr Psychiatry Neurol 2010, 23:199-205.

14. Widner B, Laich A, Sperner-Unterweger B, Ledochowski M, Fuchs D: Neopterin production, tryptophan degradation, and mental depressionwhat is the link? Brain Behav Immun 2002, 16:590-595.

15. Darlington LG, Mackay GM, Forrest CM, Stoy N, George C, Stone TW: Altered kynurenine metabolism correlates with infarct volume in stroke. Eur J Neurosci 2007, 26:2211-2221.

16. Gulaj E, Pawlak K, Bien B, Pawlak D: Kynurenine and its metabolites in Alzheimer's disease patients. Adv Med Sci 2010, 55:204-211.

17. Widner B, Leblhuber F, Walli J, Tilz GP, Demel U, Fuchs D: Tryptophan degradation and immune activation in Alzheimer's disease. J Neural Transm 2000, 107:343-353.

18. Matysiak M, Stasiołek M, Orłowski W, Jurewicz A, Janczar S, Raine CS, Selmaj K: Stem cells ameliorate EAE via an indoleamine 2,3-dioxygenase (IDO) mechanism. J Neuroimmunol 2008, 193:12-23.

19. Moroni F, Carpenedo R, Cozzi A, Meli E, Chiarugi A, PellegriniGiampietro DE: Studies on the neuroprotective action of kynurenine mono-oxygenase inhibitors in post-ischemic brain damage. Adv Exp Med Biol 2003, 527:127-136

20. Yan Y, Zhang GX, Gran B, Fallarino F, Yu S, Li H, Cullimore ML, Rostami A, $\mathrm{X} \cup \mathrm{H}$ : IDO upregulates regulatory $\mathrm{T}$ cells via tryptophan catabolite and suppresses encephalitogenic T cell responses in experimental autoimmune encephalomyelitis. J Immunol 2010, 185:5953-5961.

21. Sas K, Robotka H, Rozsa E, Agoston M, Szenasi G, Gigler G, Marosi M, Kis Z Farkas T, Vecsei L, Toldi J: Kynurenine diminishes the ischemia-induced histological and electrophysiological deficits in the rat hippocampus. Neurobiol Dis 2008, 32:302-308.

22. Kwidzinski $E$, Bechmann I: IDO expression in the brain: a double-edged sword. J Mol Med 2007, 85:1351-1359

23. Stone TW, Darlington LG: Endogenous kynurenines as targets for drug discovery and development. Nat Rev Drug Discov 2002, 1:609-620.

24. Folstein MF, Folstein SE, McHugh PR: "Mini-mental state". A practical method for grading the cognitive state of patients for the clinician. J Psychiatr Res 1975, 12:189-198.

25. Foulkes MA, Wolf PA, Price TR, Mohr JP, Hier DB: The Stroke Data Bank: design, methods, and baseline characteristics. Stroke 1988, 19:547-554.

26. The World Health Organization MONICA Project (monitoring trends and determinants in cardiovascular disease): a major international collaboration. WHO MONICA Project Principal Investigators. J Clin Epidemiol 1988, 41:105-114

27. Tombaugh TN, Mclntyre NJ: The mini-mental state examination: a comprehensive review. J Am Geriatr Soc 1992, 40:922-935.
28. Winkel-Witlox AC, Post MW, Visser-Meily JM, Lindeman E: Efficient screening of cognitive dysfunction in stroke patients: comparison between the CAMCOG and the R-CAMCOG, Mini Mental State Examination and Functional Independence Measure-cognition score. Disabil Rehabil 2008, 30:1386-1391.

29. Molloy DW, Standish TI: A guide to the standardized Mini-Mental State Examination. Int Psychogeriatr 1997, 9(Suppl 1):87-94, discussion 143150.

30. Brott T, Marler JR, Olinger CP, Adams HP Jr, Tomsick T, Barsan WG, Biller J, Eberle $R$, Hertzberg V, Walker M: Measurements of acute cerebral infarction: lesion size by computed tomography. Stroke 1989, 20:871-875.

31. Williams LS, Yilmaz EY, Lopez-Yunez AM: Retrospective assessment of initial stroke severity with the NIH Stroke Scale. Stroke 2000, 31:858-862.

32. Radloff $L$ : The CES-D scale: A self-report depression scale for research in the general population. Applied Psychological Measurement 1977, 1:385-401.

33. Anderson GM, Purdy WC: Liquid chromatographic-fluorometric system for the determination of indoles in physiological samples. Anal Chem 1979, 51:283-286.

34. Forrest CM, Mackay GM, Stoy N, Egerton M, Christofides J, Stone TW, Darlington LG: Tryptophan loading induces oxidative stress. Free Radic Res 2004, 38:1167-1171.

35. Pucak ML, Kaplin Al: Unkind cytokines: current evidence for the potential role of cytokines in immune-mediated depression. Int Rev Psychiatry 2005, 17:477-483.

36. Hackett ML, Anderson CS: Predictors of depression after stroke: a systematic review of observational studies. Stroke 2005, 36:2296-2301.

37. Narushima $\mathrm{K}$, Chan $\mathrm{KL}$, Kosier JT, Robinson RG: Does cognitive recovery after treatment of poststroke depression last? A 2-year follow-up of cognitive function associated with poststroke depression. Am J Psychiatry 2003, 160:1157-1162

38. Kivipelto $M$, Ngandu T, Fratiglioni L, Viitanen $M$, Kareholt I, Winblad B, Helkala EL, Tuomilehto J, Soininen $H$, Nissinen A: Obesity and vascular risk factors at midlife and the risk of dementia and Alzheimer disease. Arch Neurol 2005, 62:1556-1560.

39. Brouns R, De Deyn PP: The complexity of neurobiological processes in acute ischemic stroke. Clin Neurol Neurosurg 2009, 111:483-495.

40. Park SB, Coull JT, McShane RH, Young AH, Sahakian BJ, Robbins TW, Cowen PJ: Tryptophan depletion in normal volunteers produces selective impairments in learning and memory. Neuropharmacology 1994, 33:575-588.

41. Pertovaara M, Raitala A, Lehtimaki T, Karhunen PJ, Oja SS, Jylha M Hervonen A, Hurme M: Indoleamine 2,3-dioxygenase activity in nonagenarians is markedly increased and predicts mortality. Mech Ageing Dev 2006, 127:497-499.

42. Bonaccorso S, Marino V, Puzella A, Pasquini M, Biondi M, Artini M, Almerighi C, Verkerk R, Meltzer $H$, Maes M: Increased depressive ratings in patients with hepatitis $C$ receiving interferon-alpha-based immunotherapy are related to interferon-alpha-induced changes in the serotonergic system. J Clin Psychopharmacol 2002, 22:86-90.

43. Swardfager W, Herrmann N, Dowlati Y, Oh Pl, Kiss A, Walker SE, Lanctôt KL: Indoleamine 2,3-dioxygenase activation and depressive symptoms in patients with coronary artery disease. Psychoneuroendocrinology 2009, 34:1560-1566.

44. Cowen PJ, Parry-Billings M, Newsholme EA: Decreased plasma tryptophan levels in major depression. J Affect Disord 1989, 16:27-31.

45. Lucca A, Lucini V, Catalano M, Alfano M, Smeraldi E: Plasma tryptophan to large neutral amino acids ratio and therapeutic response to a selective serotonin uptake inhibitor. Neuropsychobiology 1994, 29:108-111.

46. Riedel WJ, Klaassen T, Deutz NE, van Someren A, van Praag HM: Tryptophan depletion in normal volunteers produces selective impairment in memory consolidation. Psychopharmacology (Berl) 1999, 141:362-369.

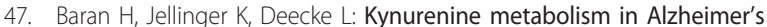
disease. J Neural Transm 1999, 106:165-181.

48. Potter MC, Elmer Gl, Bergeron R, Albuquerque EX, Guidetti P, Wu HO Schwarcz R: Reduction of endogenous kynurenic acid formation enhances extracellular glutamate, hippocampal plasticity, and cognitive behavior. Neuropsychopharmacology 2010, 35:1734-1742.

49. Amori L, Guidetti P, Pellicciari R, Kajii Y, Schwarcz R: On the relationship between the two branches of the kynurenine pathway in the rat brain in vivo. J Neurochem 2009, 109:316-325. 
50. Nozaki K, Beal MF: Neuroprotective effects of L-kynurenine on hypoxiaischemia and NMDA lesions in neonatal rats. J Cereb Blood Flow Metab 1992, 12:400-407.

51. Gigler G, Szénási G, Simó A, Lévay G, Hársing LG Jr, Sas K, Vécsei L, Toldi J: Neuroprotective effect of L-kynurenine sulfate administered before focal cerebral ischemia in mice and global cerebral ischemia in gerbils. Eur J Pharmacol 2007, 564:116-122.

52. Zhou L, Li F, Xu HB, Luo CX, Wu HY, Zhu MM, Lu W, Ji X, Zhou QG, Zhu DY: Treatment of cerebral ischemia by disrupting ischemia-induced interaction of nNOS with PSD-95. Nat Med 2010, 16:1439-1443.

53. Gendelman HE, Zheng J, Coulter CL, Ghorpade A, Che M, Thylin M, Rubocki R, Persidsky Y, Hahn F, Reinhard J Jr, Swindells S: Suppression of inflammatory neurotoxins by highly active antiretroviral therapy in human immunodeficiency virus-associated dementia. J Infect Dis 1998, 178:1000-1007.

54. Suarez S, Baril L, Stankoff B, Khellaf M, Dubois B, Lubetzki C, Bricaire F, Hauw JJ: Outcome of patients with HIV-1-related cognitive impairment on highly active antiretroviral therapy. Aids 2001, 15:195-200.

55. Huengsberg M, Winer JB, Gompels M, Round R, Ross J, Shahmanesh M: Serum kynurenine-to-tryptophan ratio increases with progressive disease in HIV-infected patients. Clin Chem 1998, 44:858-862.

56. Hachinski V, ladecola C, Petersen RC, Breteler MM, Nyenhuis DL, Black SE, Powers WJ, DeCarli C, Merino JG, Kalaria RN, et al: National Institute of Neurological Disorders and Stroke-Canadian Stroke Network vascular cognitive impairment harmonization standards. Stroke 2006 37:2220-2241.

doi:10.1186/1742-2094-8-17

Cite this article as: Gold et al:: The relationship between indoleamine 2,3-dioxygenase activity and post-stroke cognitive impairment. Journal of Neuroinflammation 2011 8:17.

\section{Submit your next manuscript to BioMed Central and take full advantage of:}

- Convenient online submission

- Thorough peer review

- No space constraints or color figure charges

- Immediate publication on acceptance

- Inclusion in PubMed, CAS, Scopus and Google Scholar

- Research which is freely available for redistribution

Submit your manuscript at www.biomedcentral.com/submit 